\title{
Imagining by Feeling: A Case for Compassion in Legal Reasoning
}

\author{
Maksymilian Del Mar*
}

\begin{abstract}
This paper argues that feeling compassion (and other relational emotions) makes an important, beneficial difference in adjudication, as it improves the exercise of the perspectival imagination, that is, it helps a judge to better understand, and to better describe, a situation as another person experienced it. Even where a judge has a highly developed capacity for empathy and sympathy (these being cognitive and evaluative processes that are distinguishable from emotions), there is something to be gained by a judge actually feeling compassion. However, given the potential for the distortion of understanding as a consequence of feeling compassion, any such feeling has to be accompanied by the robust exercise of the perspectival imagination, that is, by imagining multiple perspectives (including sometimes constructing imaginary ones), so as to avoid privileging any one perspective over others. It is further argued that this 'imagining by feeling', as I call it in this paper, is not a threat to impartiality or the rule of law, but in fact a condition of it. It is part of the rule of law that people have a right to be heard, especially those whom we may otherwise find it difficult to understand. Imagining by feeling helps judges to better 'hear' a greater diversity of those who come before them, and thus helps the judiciary to improve the quality of the rule of law.
\end{abstract}

\section{Introduction}

This paper argues for the importance of compassion in legal reasoning. The argument, in brief, is this: first, compassion (conceived of as a 'cognitively-evaluative relational feeling') improves the quality of what I will call 'the perspectival imagination'; second, the perspectival imagination is necessary to the exercise of legal reasoning - and the more its quality is improved, the better the quality of legal reasoning, both in the instant case and over time; third, therefore, compassion assists in improving the quality of legal reasoning; but fourth, recognising the dangers involved in privileging any one perspective (precisely as a result of having, via feeling, imagined it more 
richly), one must take care to exercise the 'multi-perspectival imagination' in legal reasoning - which means exercising compassion for a wide range of participants whose perspectives matter for the case at hand.

The three parts of the paper below broadly follow the above-mentioned steps of the argument. First, I articulate what I mean by cognitively-evaluative relational feelings, distinguishing them from the processes of empathy and sympathy. In this part, I also outline the process of compassion. Second, I define what I mean by the perspectival and multi-perspectival imagination, and look at the relations between emotion and imagination. And, third, I illustrate the potential for this compassionenabled multi-perspectival imagination in adjudication by reference to the DeShaney case (1989).

\section{Cognitively-evaluative relational feelings: situating compassion}

In this first part of the paper I situate my understanding of the process of compassion in three ways: first, I relate it to but also distinguish it from empathy and sympathy; second, I explain what I mean by classifying compassion as a cognitively-evaluative relational feeling; and third, I provide an outline of the process of compassion.

\subsection{Empathy, sympathy, compassion}

In order to better situate what I mean by compassion, I propose in this section to compare and contrast it to empathy and sympathy. I acknowledge the large literatures on all these terms - for present purposes, what is important is to offer stipulative definitions of them that will allow me to carve out what I take to be distinctive about compassion.

By empathy, then, I propose to mean the ability and process of understanding what another person might be experiencing and the situation in which they are 
experiencing it. Defined this way, empathy is cognitive - crucially, it need not involve experiencing any emotion, of actual feeling. Of course, the (initial and continual) development of empathy as an ability surely requires the experience of emotion, but it is not necessarily the case that any one exercise of empathy is (on this definition) an affective state or process. Further, empathy does not necessarily involve - as I argue, below, sympathy does - evaluation. It is, rather, the bare process of understanding making inferences - as to what another person may be experiencing.

Sympathy is related to empathy, but in the sense I use it here, goes one step further, that is having attempted (as in empathy) some understanding of the situation of the other and their experience of it, sympathy involves an evaluation of that experience. Sympathy, then, is cognitively-evaluative (empathy being only cognitive). This sense of sympathy is arguably close to the way Adam Smith uses the concept in his Theory of Moral Sentiments (2002 [1759]), where the impartial spectator approves or disapproves of the emotions of the person being observed - asking, for instance, 'would I, as an impartial spectator, also feel or have felt resentment in this situation?', with consequences for one's moral judgement. Evaluation here clearly depends on cognition - one must first be capable of understanding the situation of the other person before one can evaluate how they experience it. Crucially, as with empathy, we can exercise sympathy without feeling any emotion (though, again, our ability to sympathise develops as a result of emotional experiences and reflections on them as indeed Smith is at pains to show). Thus, both empathy and sympathy are cognitive processes, with sympathy also being evaluative, and neither necessarily involve feeling any emotion.

We come, finally, to compassion. I acknowledge that compassion is necessarily cognitive (like empathy) and evaluative (like sympathy). With respect to the evaluative dimension, however, one has to be careful: I will be suggesting that compassion is necessarily thinly evaluative, meaning that the other person is salient to us and that we have some concern for them. This thin evaluation is necessary, but thick evaluation is only contingent. By thick evaluation I mean approving or disapproving of their feelings, for example whether they are proportionate or deserving. But despite the 
overlap with empathy and sympathy in these ways, compassion is also different from them both in that it necessarily involves feeling. In short, the crucial point is that there is something it feels like to experience compassion - whereas this is not necessarily so for empathy and sympathy.

It is notoriously difficult to articulate what is meant by 'feeling'. I also acknowledge the debate in the literature on emotions as to whether emotions require feelings. Later, when I speak of the process of compassion, I refer to feeling some of the suffering one takes another to be in, and then feeling sadness for that suffering. These states may be experienced in different ways, but it seems to me arguable that they include: (a) some bodily changes (which are likely to differ across people), for instance a certain heaviness in one's stomach when feeling some of the suffering one takes another to be in; and (b) a more immediate focus or concentration upon the object of one's emotion, which may include a greater readiness or willingness to perform some action with respect to that object. It is important for my argument that this action may refer to imagination - to (as I will articulate it later) the mental activity of constructing images of possibilities and alternatives - for I shall be arguing that by feeling, we imagine more richly. Compassion, then, includes experiencing these states, and in this respect, compassion is unlike empathy and sympathy. The latter are more distant from the object and one's actions, less focused, less self-involving - and, again, crucially for my argument, less likely to stimulate the imagination.

\subsection{Cognitively-evaluative relational feelings}

Emotions, for present purposes, are then cognitively-evaluative feelings. By thinking of emotions in this way, I express solidarity with those theories that treat emotions as intelligent, as 'concerned with receiving and processing information' (Nussbaum, 2001, p. 23), and to some extent as judgements or appraisals of value. Compassion is an emotion - and it is thus also a cognitively-evaluative feeling. However, it is a particular kind of emotion. To help see this, let me draw an analytical map of some of the different dimensions of emotions. 
For a start, emotions can have three objects. Our emotions can be: (1) worlddirected (as when we fear something in the environment, for example a tidal wave, a storm etc.); (2) self-directed (as when, for instance, we experience self-pity, or are scared of ourselves); ${ }^{1}$ and other-directed emotions (what I call 'relational emotions', of which compassion is one). The point of making such distinctions is that there may well be different cognitive and evaluative abilities that are exercised, or exercised in different ways, depending on the objects our emotions are directed to.

Relational (that is, other-directed) emotions can be further broken down in various ways. First, one can distinguish between three different modes of interaction: first, one can experience relational emotions in a directly interactive (secondpersonal) way, for example in face-to-face interaction; second, one can experience them communally, as when, for instance, one feels safety in numbers; ${ }^{2}$ and third, one can experience them spectatorially. Once again, there may be different abilities at stake in these different modes - for example, one must surely be quicker, make faster guesses, more fragile and tentative inferences, in a direct interactive encounter than one can (usually) afford in the spectatorial mode. The spectatorial mode itself, however, can also be further broken down: arguably, it makes a difference whether one is actually observing someone and their situation (for instance, witnessing an accident on the street) - the 'observational' sub-mode - or reading a report / description of it (as in a novel, or a witness statement) - the 'testimonial' sub-mode. For the purposes of this paper, I am interested in the spectatorial mode of relational emotions, and especially those in the testimonial sub-mode, namely those that are experienced in the course of reading a report or hearing a description of someone else's experience. Thus, I acknowledge that compassion can be experienced in various modes of interaction, but I focus here on it as experienced in the spectatorial (testimonial) mode.

Further, one can also break down relational emotions into non-mediated and mediated ones. Thus, one can speak of the emotions we experience vis-à-vis others in

\footnotetext{
${ }^{1}$ Shame and guilt are more complex - they may be a mix of other-directed and self-directed emotions.

${ }^{2}$ I owe this point to Dermot Feenan.
} 
a way that is not mediated by another emotion, for example one can feel envious of another. But one can also experience a relational emotion that is first mediated by another one - for instance, in compassion one arguably needs to experience some of the suffering ${ }^{3}$ one takes (knows or infers) the other to be in, before one feels sadness for them. One can think of other examples too: schadenfreude or emotions closely related to compassion (such as pity). For the purposes of this paper, I am interested in the mediated relational emotions.

In sum, then, for the purposes of this paper, I focus on compassion as a mediated cognitively-evaluative relational feeling, experienced in the spectatorial (testimonial) mode.

\subsection{The process of compassion}

Situated in the way I have above, it is important now to outline the process of compassion. The first point to make is precisely that it is not a state or episode, but a process - a temporally-extended series of linked (mental and bodily) states. There is a tendency to sometimes speak of emotions as immediate, transitory and sudden and of persons being swept up by them. This way of thinking about emotions tends to be connected to thinking of them as opposite to reason, as non-cognitive or nonevaluative, or as non-intelligent. I acknowledge that it is important not to lose sight of some emotional experiences being (somewhat) like this - but on the whole, and in keeping with the above cognitively-evaluative positioning of emotions, I am proposing here we think of emotional experiences as complex, multi-layered, multi-stage processes, in which a mixture of abilities (cognitive, evaluative, and at various levels of development and dexterity) is exercised. It is also important to emphasise that reflection can be part of an emotion, and that it arguably necessarily is part of some particularly complex emotions (especially those, as above, that are mediated).

\footnotetext{
${ }^{3}$ I acknowledge there is a large literature on the distinction between pain and suffering. For present purposes, I refer to suffering as this is arguably the more inclusive concept.
} 
Compassion, as a process then, can be thought of as - at the very least containing the following five stages:

1. A thinly cognitively-evaluative state of both awareness of another person (as being an other) one is interacting with, observing or imagining, accompanied by - and this is really inseparable from that awareness - an interest in or concern for that other person. Another person, then, must be both cognitively and evaluatively salient for one - they must be in the sphere of one's phenomenal (whether sensory or imaginative) reach and interest. This salience of and interest in the other can either be voluntary or involuntary (for example, our attention and interest can be prompted by some loud or sudden noise, or we can make ourselves focus on some other without being prompted to do so).

2. Stimulated by this initial awareness and concern / interest, one then needs to exercise further cognitive effort, imagining the other's situation and perspective. In this second stage, however, one need not yet feel any emotion (aside from that initial interest in / concern for the person, as per stage 1). It is also part of this stage that one begins to take the other person to be suffering - as a result of imagining something of their situation and perspective, one cognises that they may be suffering.

3. Having imagined something of the other's situation and their perspective of it, and inferred that they may be suffering, in the third stage one then feels something of the suffering that one has imagined the other person to be in. It is important to emphasise that one cannot assume that one is feeling the same as what the other person is in - one is merely feeling something of what one imagines or takes the other to be suffering. One can be entirely mistaken about this - one may, for instance, have misread the expressions of another person, possibly as a result of cultural differences. It is, thus, an important part of the 
process of compassion that one is aware of the possibility that one has misinterpreted what state the other person is in. In that sense, self-reflexive humility is an important part of the process of compassion. Nevertheless, I take it to be key to the process of compassion that one actually feels some of the suffering that one has taken or imagined the other to be in.

4. Having felt something of the suffering one imagines or takes the other person to experience, one is then likely to return to imagining the situation of the other and their perspective on it. Indeed, there is likely to be a multiple backand-forth between feeling some of what one takes to be the suffering of the other and imagining (increasingly more richly) their situation and perspective. The two processes are naturally difficult to disentangle (I am disentangling them somewhat artificially for analytical purposes). As I will go on elaborate, feeling some of the suffering one takes the other to be in stimulates one to imagine the situation from their perspective more richly, and imagining it more richly, may well stimulate one to feel more of the suffering one imagines them to be in.

5. Finally, having both imagined and felt some of the suffering of the other person, one then feels sadness for their suffering. ${ }^{4}$ This is also a crucial step, without which there is no compassion. One has to be capable of stepping outside the perspective of the other, and experience the feeling (that one has oneself, as oneself) for another's suffering. The feeling of sadness for another's suffering may also result in one returning to imagine the situation and

\footnotetext{
${ }^{4}$ This feeling is more complex than I can describe here. One point to make is that feeling sadness for the suffering one imagines another to be in need not necessarily equate to condescension. Thus, a person observing runners training for a marathon, may experience compassion for them (including feeling sadness for their suffering as she imagines it), even though she believes that this suffering is something they have voluntarily chosen and that, in their own eyes, it is good for them (e.g. that getting through the training it will make them better runners). One can, then, experience compassion for others while at the same time recognising and respecting their independent agency.
} 
perspective of another more richly, and to better understand the suffering they may be in, thereby also intensifying the feeling of sadness for another.

These are the minimal bones of what is a multi-layered, multi-stage, and also backand-forth, dynamic process of the emotion of compassion.

To this basic structure, one may add several extra elements. Space will not permit me to discuss these in detail, so let me simply flag two of them. For some, most notably Nussbaum (2001, pp. 311-315), there is necessarily a stronger evaluative element in compassion, namely the evaluation of the other's suffering as undeserved. I suggest that it is possible for me to experience sadness for the suffering I take another to be in without having evaluated them as undeserving. Yet more strongly, though also more rarely, it is also possible to experience that sadness even after having evaluated someone as deserving of suffering. I acknowledge that this requires effort and may be a question of skill - one may need to train oneself to be able to experience sadness for the suffering of those who one either does not evaluate as undeserving of it, or that one does evaluate the other as deserving of that suffering. Indeed, this may be a crucial skill (let us call it the skill of overcoming strongly evaluative compassionate resistance) in many circumstances in which one is given the task of evaluating the conduct of a wide variety of persons (as judges in legal institutions are). For these reasons, I would consider this stronger evaluative element a contingent one. I would also regard as contingent Nussbaum's other condition, namely that the suffering for the other be serious rather than trivial (see Nussbaum, 2001, pp. 306-311). Treating the other's suffering as serious may be part of some experiences of compassion, but I also think it is possible to experience compassion for what may initially strike one as trivial, but which one comes to revise (precisely as a result of the process of compassion) as serious for that particular person. 


\section{Compassion and the (multi-) perspectival imagination}

In the above outline of the process of compassion, imagination played a key role. In this part of the paper, I want to zero in on this relationship between compassion and the imagination. I do so in two steps: first, discussing the sense in which the imagination can be perspectival and multi-perspectival; and second, turning to the relationship between emotion and imagination. I do so with a view to indicating, later, the importance of imagining (richly, as a result of feeling compassion for) the perspectives of (multiple) others in the process of legal reasoning.

\subsection{The perspectival and multi-perspectival imagination}

The perspectival and multi-perspectival imagination is a sub-set of imagination in general. The philosophical debate over the bounds of the imagination has intensified in the past few decades, and it has become common to speak of the variety of exercises of the imagination, all needing to be carefully distinguished. ${ }^{5}$ While acknowledging that there is little in these debates that is not controversial, I offer the following stipulative definition of the imagination for present purposes: it is the process of deliberately ${ }^{6}$ and effortfully constructing mental images ${ }^{7}$ of what it might be like for someone else to experience a certain situation.

\footnotetext{
${ }^{5}$ See, for instance, Stevenson (2003) and Kind (2013).

${ }^{6} \mathrm{I}$ acknowledge, naturally, that imagination can be spontaneous or even unconscious (as in dreams - see Spaulding, 2016), and I also acknowledge that even in cases of deliberate imaginings (as also for instance in the use of thought experiments in science and philosophy) there will be plenty that we imagine non-deliberately. We are, in short, never in complete control of our imaginings - but, equally, our imaginings are often constrained by our knowledge of reality (so they are not entirely flights of fancy). For more on how imagination is constrained, see Kind and Kung (2016).

${ }^{7}$ Again, there is a robust and long-standing debate as to whether images are necessary for imagination (for a defence, see Kind, 2001). I think that it is possible to imagine without mental
} 
This definition already - in its final feature - references the idea of perspective. Indeed, for a number of philosophers, perspective is the key feature that differentiates thinner, typically propositional imagining (for example, imagining that, or also supposing or conceiving) from thicker, non-propositional imagining. Thus, for instance, Richard Moran in a classic paper, distinguishes between the 'hypothetical and dramatic imagination' (1994, p. 104), arguing that the latter involves adopting a perspective, and as a result requires a different kind of effort, and with different things at stake for the imaginer. ${ }^{8}$ More recently, Magdalena Balcerak (2016) has also argued for a distinction between supposing, conceiving and imagining, on the basis that it is only in imagining that we adopt 'experiential perspective-taking' (2016, p. 49). Like Moran, Balcerak stresses the self-involvement of this perspective-taking, saying that it involves putting 'myself in the position of somebody who actually perceptually experiences [for example] an apple' (2016, p. 49).

I think there is an important ambiguity in this way of thinking about perspective - namely, as something self-involving. I suggest it is crucial to keep in mind two kinds of imagining the perspectives of others: first, one can project oneself into the situation and experience of another, asking 'what would I feel if I was in that situation?', or, second, one can instead consider all that one knows about that person and their situation and ask, 'what might that other person be experiencing in that situation?' The second is a more robust way of exercising the perspectival imagination; it arguably requires greater sustained, imaginative effort to try to understand how another person might be experiencing a certain situation. ${ }^{9}$

\footnotetext{
imagery, but this is often a matter of definition (e.g. if one includes supposing or conceiving in one's definition, then one will think it is possible to imagine without imagery).

${ }^{8}$ Moran says that in the case of dramatic imagination, 'more is revealed and given of oneself than in the case of ordinary counterfactual reasoning' (1994, p. 105).

${ }^{9}$ See Coplan (2011), who is also drawing on the work of Peter Goldie: 'In other-oriented perspective taking, a person represents the other's situation from the other person's point of view and attempts to stimulate the target individual's experience as though she were the target individual. Thus, I imagine that I am you in your situation...I attempt to simulate your experiences from my point of view... Empirical studies have shown that other-oriented perspective taking requires greater mental flexibility and emotional regulation...than selforiented perspective-taking... (pp. 54-55).
} 
For these reasons, I prefer not to focus on this distinguishing feature of perspective. ${ }^{10}$ Instead, I want to draw on a different kind of distinction - argued for by Joshua Landy in his work on Proust (2004) - namely, the distinction between perspective and viewpoint (or point of view). In brief, a viewpoint is something that we might share in common with others - it is literally the angle from which we might look upon a situation. Thus, we can think of standing and facing in a certain direction, and from that viewpoint seeing a series of church steeples. A viewpoint, then, is not something that uniquely belongs to that other person. A perspective, however, goes considerably further than something we can all see from a certain viewpoint. According to Landy:

...if we wish to learn something about the inner 'world' of another individual that aspect of her perspective which is not held in common with the rest of humanity - we can do so only by studying the combinations that she typically (and unconsciously) produces among the elements of any given domain. (2004, p. 60)

In the case of Marcel's perspective - Marcel being the character that Proust explores in his great novel - we must therefore pay attention to the associations and connections that inform his own construction of the situation. Perspective is an active, affectively-rich, meaning-constructing process. It takes time and effort to learn anything - even a small fraction - of someone else's perspective (for Proust, a master, it takes many years and over four thousand pages). We learn something about Marcel's experience of the steeples from the following quotes (in a piece of writing by Marcel that we are made privy to by Proust):

\footnotetext{
10 I leave for another occasion the very interesting idea that in the other-oriented kind of imagining others, the self may still be necessarily involved in some way.
} 
The minutes passed, we were travelling fast, and yet the three steeples were still a long way ahead of us, like three birds perched upon the plain, motionless and conspicuous in the sunlight... ...a little later, when we were already close to Combray, the sun having set meanwhile, I caught sight of them for the last time, far away, and seeming no more now than three flowers painted upon the sky above the low line of the fields. They made me think, too, of three maidens in a legend, abandoned in a solitary place over which night had begun to fall. (Proust, quoted in Landy 2004, p. 52)

Birds, flowers and maidens - the steeples are constructed to have a meaning by Marcel; those associations and connections refract his interests, needs and values (see Landy 2004, p. 60). Proust here is giving us access to Marcel's perspective - and not just the viewpoint from which he sees the steeples.

For Landy, there is similarity between the way Proust articulates and explores Marcel's perspective and the perspectivism of Friedrich Nietzsche ${ }^{11}-$ and drawing this out will allow me to introduce the idea of the multi-perspectival imagination. According to R. Lanier Anderson, who Landy draws on, 'a perspective [is] a way of organising our experience', and this is not because of some Kantian transcendental concepts that make experience possible, but because of our 'contingent' and 'variable' set of 'needs, interests and values' (1998, p. 3). What Proust adds here, arguably, is that he shows very concretely just how such needs, interests and values manifest themselves in how persons (especially Marcel) experiences the world and others. More explicitly, Proust shows us that we cannot rest content with the abstract thesis that experience is perspectival in the sense Nietzsche means that (as above). Rather, in order to imagine another's perspective, we must try to visualise - in imagination those needs, interests and values in the concrete experiences of persons in their relations with the world and others.

\footnotetext{
${ }^{11}$ Indeed, for Landy, 'the Proustian view [is] a sophisticated (and unwitting) refinement of Nietzschean perspectivism' (2004, p. 57).
} 
But Nietzsche also adds something - which perhaps Proust does not do enough of in the novel (given the focus on Marcel). At stake is the usual problem with any more general (philosophical) celebration of perspectivalism - namely, relativism and epistemological / normative anarchy. Nietzsche deals with that challenge - 'what now for objectivity? Are there any standards?' - by saying that the idea of objectivity as a form of 'contemplation without interest' (neutrality, the view from nowhere, or nonperspectivism) is 'a nonsensical absurdity', adding more positively:

The idea is that different perspectives reveal different aspects of things, and that the pursuit of objectivity is just the attempt to broaden one's perspectives by using others to take account of aspects of the world obscured by one's own... the more affects we allow to speak about one thing, the more eyes, different eyes, we can use to observe one thing, the more complete will our 'concept' of the thing, our 'objectivity', be. (Nietzsche, quoted in Anderson 1998, p. 18)

Perspectivism, then, does not collapse into relativism, but neither does it mean we must adopt non-perspectival objectivism. Instead, we are enjoined to improve our knowledge - for example of some situation, or some issue - by seeing how differently it is constructed by multiple perspectives (how different needs, interests and values are refracted concretely in particular experiences of that situation). Indeed, our knowledge is further improved by not only constructing what that situation might be like from multiple other perspectives, but in switching back-and-forth between them. ${ }^{12}$ The multi-perspectival imagination, then, is valuable because by deploying multiple perspectives we can construct a more complete (but never entirely complete) picture of the constellation of needs, interests and values at stake; and this value is

\footnotetext{
${ }^{12}$ See Anderson (1998, p. 19), for an example of medical decision-making that benefits from perspective-switching.
} 
enabled by the task of perspective-switching, including the experience of friction (axiological, affective) between different perspectives. ${ }^{13}$

Thus, to summarise on the topic of imagination: by the imagination in general I mean the process of deliberately and effortfully constructing mental images of what it might be like for someone to experience a certain situation; by the perspectival imagination, I mean more than seeing a situation from a certain angle (viewpoint) - I mean the active construction (in mental imagery) of the needs, interests and values of another person as they are refracted in the concrete and particular experiences of persons in their relations with the world and others (for instance, via the associations and connections they make between things in their experience); and by the multiperspectival imagination, I mean the process of constructing a variety of such perspectives, and switching between them, thereby accumulating greater knowledge of a situation. Imagining the perspectives of others requires a) resisting my own background knowledge and attempting to characterise the other as richly as one can; b) recognising that this process is a difficult one, which requires training and development; and c) exercising humility, in particular by recognising the necessary incompleteness of any one attempt to imagine the perspective of another.

\subsection{Emotion and imagination}

Having articulated what I mean by relational emotions and the perspectival and multiperspectival imagination, it is now time to turn to the relationship between them - a relationship that, as I will indicate in the final part of the paper, is important for the quality of legal reasoning. In doing so, I will be drawing mainly on Adam Morton's Emotion and Imagination (2013). Morton makes some bold (though also interesting) claims as to that relationship - for instance, asserting that 'all emotion involves imagination' (2013, p. 3); that imagination 'can be seen as a special case of emotion'

\footnotetext{
${ }^{13}$ This process of perspective-switching deserves more attention than I can afford it here. It is a topic (including the above-mentioned experience of friction) that has been explored, for instance, in literary theory (see e.g. Hartner (2012) for an overview, citing in particular the work of Uwe Lindemann on friction).
} 
(2013, p. 21); and that '[p]erhaps emotion made thought [including imagination] possible' (2013, p. 21). I am not here concerned with whether one is the sub-set of the other, or whether one makes the other possible. Indeed, for present purposes I can concede that we can experience emotion without the imagination, and that we can imagine without experiencing emotion. What is most helpful and important, however, is Morton's idea that 'emotion has an object and involves imagining scenarios around it' (2013, p. 30), and more elaborately, that '[h]aving an emotion typically involves a complex of imagined possibilities, imagined reactions to them, and imagined sensations, and these imaginations are much of what the fear [or some other emotion] feels like' (2013, p. 33). I have already spoken of emotions as complex, multi-layered processes. With Morton's help, I now suggest that: (a) part of what makes emotions complex is that they often (though not necessarily) involve some imagination indeed, sometimes a great deal of imagination; and (b) that part of what makes at least the perspectival imagination distinctive (from other kinds of imagination) is that it is typically accompanied by emotion - and, again, sometimes by a great deal of emotion - such that typically there is something it feels like to imagine how someone else might be experiencing a certain situation.

Further, and this is also critical for present purposes, Morton notices that in many cases emotion (and here I would include compassion) increases the richness and vivacity of imagining, which might further increase the intensity of the experience of an emotion. The relationship, then, is not only one of overlap at the same time, but also mutual stimulation over time. Here is one example he gives:

...think of someone watching a skier approach an icy downhill run. She thinks of the run as very dangerous today, and wonders if the ski patrol are on duty. She is not worried about that skier so much as generally apprehensive about current conditions. Then she recognises the skier as her child, and suddenly she visualises all the bends on the run where one might fall, the trees one might run into, the moguls in surprising places, and has an impulse to rush down the run herself to give first aid, or take another route and alert the 
patrol... She even has a stray thought of wolves in the woods preying on fallen skiers, and then a fantasy of her own car breaking down in a snowstorm so that she freezes before she is found. (2013, p. 32)

The observer here first begins to imagine more richly on the back of an increase in feeling (of greater concern, having recognised the skier as her own child). Imagining more richly, in turn, intensifies her emotion (of concern for, fear of, her child), and this intensification of emotion further spurs her imagination, not only more richly, but even quite extravagantly (for example, imagining wolves). We can also surely relate to this example in various ways: we can think of other circumstances in which we have felt fear, where part of what it is like to feel fear is to imagine, indeed for the imagination to almost take over (for example, childhood fears of darkness, and imagining what was under the bed). But we can extend the example considerably beyond fear - consider jealousy, for instance, or resentment. Part of what it is to feel jealous (and what it feels like to experience jealousy) is to imagine what a beloved is up to with someone else - and, to imagine such scenes is to intensify the feeling of jealousy.

The same dynamics as to the mutually reinforcing relationship between emotion and imagination are at play in the case of compassion. Part, then, of the process of compassion is to imagine (concretely, with mental images) someone's suffering in situation - understood from their perspective. The initial salience of and interest in another stimulates an initial act of imagining the situation from their perspective. This initial act of imagination, in turn, stimulates feeling (in compassion, feeling some of the suffering one imagines the other to be experiencing). This feeling, then, stimulates the perspectival imagination further. The more one feels, the more one imagines - and vice versa. In other words, the more one feels, the more richly one constructs the concrete associations and connections one takes to be constituting the other's perspective. What is critical here is to see the relation (in time and over time) between the perspectival imagination (again, in its concreteness - and in concreteness 
from a perspective, that is as filtered by that person's needs, interests and values) and the feelings one experiences as part of the process of compassion.

Morton's example, of course, also illustrates various dangers - the imagination, stimulated by emotion, can construct wildly implausible possibilities; and, the fact that we imagine more richly may be caused by bias, that is by who or what we are already predisposed to care about. These dangers are real, but I do not think they warrant the conclusion that we should thus dismiss the value of feeling imaginatively or imagining by feeling - that would be to give up on the considerable insights that engaging in such imaginative acts can provide (precisely into the perspectives of others). Thus, to the contrary, I would argue (along with Nietzsche) that we should instead (at least in contexts of judgement) exercise the multiperspectival imagination. Aiming to understand better a certain situation, we do not withdraw into allegedly non-perspectival abstractions, but instead enter into multiple concrete perspectives - and, in order to increase the quality of our imagining those perspectives, we do so with feeling. It is, to repeat, only by feeling that we can get closer to (by imagining, of course always imperfectly) the concrete and particular experiences of someone else's perspective.

There is one final and important aspect to this affective dimension of imagination that I wish to mention, before going on in the next part to briefly illustrate the argument in the adjudicative context. That is the role of emotion in what is referred to as 'imaginative resistance'. As Balcerak explains it, 'imaginative resistance occurs when a subject is asked to imagine a particular situation, but is either unable or unwilling to do so' $(2016$, p. 47). She goes on to claim that 'most convincing examples' of it 'involve requests to imagine situations where morally highly deviant behaviour and attitudes are endorsed', for example confronted with the case of Alice, who 'took her new-born baby, put it into a cotton bag, closed the bag tightly with a rope, and threw it into the lake', there may be resistance to imagining the scene, let alone Alice's perspective (2016, p. 47). What Balcerak does not address here is the role of emotion - and yet, that role must be considerable. Faced with such an example there may be not only resistance to imagining - but also anger (moral anger, or even 
outrage) against Alice, as well as stomach-churning sickness to imagining the scene (which leads to further resistance). Thus, just as imagining more richly is tied to emotion (in the ways I have discussed above), so is refusing to imagine or resisting imagining. Such resistances may be tolerable if reading a novel or watching a play or film - but they are different if the reader is tasked with evaluating Alice. What one needs to develop, then, is an ability to deliberately feel - in this case, some of Alice's suffering, and then sadness for her - in order to not only better imagine her perspective, but also to challenge (and move somewhat beyond) resistance to imagining it. This is necessary if Alice is to be given the respect she deserves, not as someone who has murdered their baby, but as a subject of others' judgement.

\section{The adjudicative context}

In this third, and final, part of the paper, I wish to point - and I can only point, in a sketchy way - to how we might see the above account of compassion - as a cognitively-evaluative relational emotion linked closely to the perspectival imagination - in the context of exercising legal judgement. I do so by reference to the now (in)famous case in the law and compassion literature, namely the DeShaney case (1989).

My argument, in general, is that actually feeling compassion will improve the quality of legal judgement. This is because the quality of a legal judgement depends in part on how well the multi-perspectival imagination is exercised by the judges, and that exercise, in turn, depends on actually feeling compassion - especially in cases (which are likely to be common) where judges might otherwise resist imagining. I have already argued for a conception of compassion as a complex, multi-layered, multistage process, which involves (again, as I have developed it above) the perspectival imagination. Compassion - to reiterate the point once more - stimulates the perspectival imagination. ${ }^{14}$ What now needs to be developed is the connection

\footnotetext{
${ }^{14}$ This is the crucial difference between the argument being presented here and the defence of empathy in Corso (2014), or of 'the compassionate stance' or 'empathic point of view' in
} 
between the use of the multi-perspectival imagination and the quality of a legal judgement.

There are three principal reasons why the multi-perspectival imagination is so important for the quality of a judgement: ${ }^{15}$ first, it assists judges in better applying legal concepts - which I would extend to those beyond constitutional / human rights, to all kinds of legal concepts (for example, economic duress, or offer and acceptance); second, by describing the perspectives of various stakeholders in the dispute, judges in the present case provide better resources for future courts; and third, it shows greater respect to parties coming before one and seeking a hearing. For reasons of space, I discuss only the first two in the next section. The first two are best discussed in the context of a particular case, and the third will be returned to in the final section below. ${ }^{16}$

The skeleton facts ${ }^{17}$ of the US constitutional case of DeShaney are well known: a child, Joshua, was subjected to multiple beatings by his father. After receiving complaints, a county department of social services took various steps to protect Joshua (including briefly taking Joshua into care, and away from the father, only to hand him back, though under the regime of regular visits by a social worker). Eventually, the father beat the boy so badly that he suffered permanent brain damage. A suit was filed, by the representatives of the child, against the county on the basis

Zipursky's classic paper (1990). In both cases, there is an emphasis on the cognitive, but not on the affective dimension of emotion.

${ }^{15}$ There may be other ways in which one could articulate / taxonomise the importance of the multi-perspectival imagination for legal reasoning, e.g. one could point to its significance for 1) the quality of deliberation (recalling the difficulty of imagining, and also the benefits of perspective-switching, one could argue that this slows down our deliberation, helping us to distance ourselves from impulsive reactions to facts, and thus our biases, generating time and space for more careful reflection); 2) the quality of the justification (thus the quality of the reasons, and their ability to balance more of the relevant interests, needs and values at stake); and 3) the quality of description (i.e. of the facts, and especially the role of certain persons). 16 The argument, in brief, would be that if one understands the rule of law - as Neil MacCormick did (2005) - as, in part, enabling a public space in which one can be heard, and if feeling compassion helps improve one's ability to imagine the perspectives of others, then compassion is not a threat, but rather a condition of impartiality and the rule of law.

17 In referring to them as 'skeleton' I by no means wish to suggest that the particular description that follows is in any way basic or neutral - like any description of any facts, it is necessarily narratologically and affectively charged. 
that they had deprived the child of his liberty interest in bodily integrity, in violation of his rights under the substantive component of the fourteenth amendment's due process clause. The majority found in favour of the county, interpreting the due process clause as not imposing an affirmative duty on the county to protect the child from private violence and thus not requiring the county to guarantee some minimum level of protection. There were two famous dissents - Justice Brennan's and Justice Blackmun's (it being the latter's cry of 'Poor Joshua!' that catapulted this case into an anchor for the literature on law and compassion).

Others who have discussed this case (especially Zipursky, 1990) have shown how the quality of the judgement could have been improved (if informed by compassion) in various ways, for example; in the characterisation of the facts, in the interpretation of relevant past precedents, and in interpreting various related concepts. Improving the application of concepts is one of the reasons I gave above for the importance of imagining perspectivally. Let me say more about that now. Zipursky is certainly right to point out that a great deal more could have been articulated from the perspective of the child in this case - especially as it pertains to 'deprivation of liberty'. ${ }^{18}$ Thus, the judges might have better understood how Joshua could be said to have been abandoned by the county department and its social services - this they could have done by imagining more richly what it might have been like for Joshua to be returned to his father's house, with only regular visits from the social worker to protect him. Even if the judges did not in the end adopt the abandonment dimension of deprivation of liberty, articulating it would have offered a more nuanced, more complete application of the concept (as well as some of the relevant precedents) - for a start, having considered it, the judges would have had to provide reasons why the concept ought not to be stretched to include abandonment.

What I would add to Zipursky's valuable analysis here is this: it is important for judges to experience compassion for Joshua here, and to do so not symbolically - in a moment, merely expressing sadness for Joshua's fate - but as part of the complex,

\footnotetext{
${ }^{18}$ Zipursky provides other illustrative examples of the importance of what - in my terms involve the exercise of the perspectival imagination. See his discussion of the application of the concept of 'unfairness' (1990, p. 1135) and 'inferior treatment' (1990, p. 1137).
} 
multi-layered, multi-stage process I referred to above, which includes imagining concretely what it might have been like for Joshua to have been returned to the father's home and to have been left there. We might think, on first blush, that this is unnecessary when it appears to be so easy to experience compassion for Joshua in this case. Actually, however, compassion is never easy - it is difficult and effortful, for it requires concrete imagining of another's suffering. Indeed, sometimes if compassion for one of the parties appears obvious, judges may feel like it is their duty not to say too much about it - precisely for fear of being cast as too biased and not impartial enough (arguably, one sees evidence of this attitude in the majority judgement of the DeShaney case). Thus, in this case, a great deal more could have and arguably should have been described of what it might have been like for Joshua to have experienced this situation - including the possibility that he, in some ways, enjoyed his father's company and the comfort of his home, but that he might have also have felt entirely defenceless, without anywhere or anyone to turn to for help and support. What were Joshua's options, when he was faced with his father's aggression? Could Joshua appeal to the social worker when she visited - again, from his perspective, was this likely (especially if the father was present, or even if not, would he have felt comfortable saying something to the social worker in his own home)? All this could help better probe the normative bounds of the concept of 'deprivation of liberty'.

Of course, it would be inadequate and misleading to argue merely that the quality of the judgement could have been improved if the judges had taken greater care to imagine better Joshua's perspective. That would be to argue for something like particularised-compassion-as-trumps - which carries with it all the dangers (especially bias, and the blindness of favouring one perspective because one feels compassion for it) that critics of the emotions have articulated many times. The key here is to add the multi-perspectival. Indeed, the DeShaney case is a good example of how the quality of the judgement would have been improved if the judges better imagined a wider variety of perspectives. These include not only Joshua's, but also: 
1. The perspective of the parents, for instance the father: given the high likelihood of imaginative resistance to the father's perspective, it becomes all the more important to voluntarily and deliberately - with difficulty and effort - go through the process of compassion, including imagining what the situation might have been like for the father. This includes having the son initially taken away from him, the visits by the social worker, and then losing the son as a result of having beaten him. This may be relevant, for instance, to understanding what is at stake for parents - what needs, values and interests become important - when their relationship with their children is affected by the oversight of a child protection agency. It may also be important as a check against drawing on Joshua's perspective too heavily. My suggestion here is that it is not enough to assume that one knows (in the abstract) what needs, interests and values are at stake - instead, one comes to acquire (build up) knowledge of those needs, interests and values by imagining richly particular perspectives. With some perspectives - as with the father here - there is likely to be very strong resistance to imagining, and it is here that deliberately undergoing the process of compassion can help to overcome that resistance.

2. The case-worker's perspective: a lot was said in the case that put the social worker here in a very bad light - for example Justice Brennan says that the detail of abuse 'chronicled by the social worker...seems almost eerie in light of her failure to act upon it' (DeShaney, p. 209) - and, once again, a certain amount of imaginative resistance is likely to be experienced with respect to the social worker's perspective. It is, however, important to understand, for instance, that the social worker has to act in an incredibly difficult dual role in such cases: she is both an advocate for the family as well as an enforcer of the child-protection policy. She has to use her judgement to balance these two roles in particular cases. Attempting to balance these contradictions and pressures can cause suffering for a social worker, as when, for instance, she agonises over whether she has made the correct decision not to intervene further. It is dangerous (and lessens the quality of the judgement) to be too quick and judge her actions, without attempting to better imagine her 
perspective. Further, it is a sign of respect for her, and for social workers in general, that one attempts to imagine richly what the situation may have been like for her.

3. The perspective of the local department of social services: this may seem like the most surprising suggestion of all - can we feel compassion for, and imagine the perspective of, an institution? It seems to me possible to imagine the needs, interests or values of an institution - and how, for instance, they may be affected by the decision one makes in the case (here, especially if one finds in favour of Joshua). Justice $\mathrm{O}^{\prime}$ Connor did indeed refer, in the oral argument, ${ }^{19}$ to a concern that if the argument of the petitioners was upheld, the effect on state departments might be that they would not be able to undertake child protection services at all. One can, surely, imagine - more or less richly - not only the immediate impact on the institution (those who work there and may lose their jobs), but also those to be affected by the institution not being able to offer such services (other children and families). In that sense, then, one can imagine the perspective of the institution, and if one can do that, then arguably one could also feel compassion for all those persons affected by what the institution does (or may not do in the future). The point here is that it improves the quality of legal reasoning to consider, in some richness, the needs, values and interests at stake from the perspective of the institution.

Taking into account these perspectives - imagining them, in their concreteness and particularity - is not just a matter of improving the quality of the application of relevant concepts in the instant case. It is also a matter of providing better resources for future courts. The description of facts - often multiple descriptions in multimember benches - is one of the key features of the resourcefulness of the common law. It is certainly something that complexifies the task of judges and in general makes the system less efficient in the long-term. However, it produces vital normative

19 See minute 8.47 in the oral argument, available here: https://www.oyez.org/cases/1988/87-154 (last accessed 26 June 2016). 
resources, for it gives future courts access to a highly contextualised set of normative judgements, in which there is room for exploring differences and similarities between fact patterns. There is no doubt that recommending to judges that they exercise the multi-perspectival imagination, in a way that is accompanied (because it is so effectively stimulated) by compassion, would complexify the task still further. There will be a limit, clearly, to how much of such imagining - and the correlate describing judges will be able to engage in. But it is vitally important that they do - not only because it gives them insight into the needs, interests and values at stake in the decisions they are making, but also because it allows them to communicate this to future courts.

The resourcefulness of the common law is its anchor to particular facts - and not abstract statements of principle - for it is that which allows future courts to take more measured, careful, nuanced decisions. The richer description of particular facts that results from the exercise of the multi-perspectival imagination enables that further - and this is especially important in cases where there are needs, interests and values that can easily be missed or neglected as a result of a tendency to resist imagining certain perspectives.

\section{Conclusion}

Compassion stands out as one of the most important emotions for the adjudicative context. It does so as one of the paradigmatic relational (that is, other-directed) emotions. It also does so because it is often associated with mindless bias - something that, if experienced, is sometimes thought to be more likely to lower the quality of legal reasoning, and endanger impartiality and ultimately the rule of law. My aim in this paper has been to defend the case for compassion in legal reasoning, and to do so via its role in helping us to imagine the perspectives of others more richly, including helping us to overcome instances of resistance to imagining certain perspectives. The process of compassion may be the best instrument judges have to hear and show respect to the perspectives of persons who come before them. Further, it may be the 
best instrument for supplementing the inadequacy of knowledge that deals in abstractions - it may, in short, be the best way for keeping the law anchored to one of its key strengths, namely awareness of multiple constellations of concrete needs, interests and values at stake in the resolution of conflict.

* Department of Law, Queen Mary University of London. M.delmar@qmul.ac.uk. I owe great thanks to Dermot Feenan, both for the invitation to the original workshop (and the opportunity to comment on a wonderful paper by Susan Bandes) and for subsequent discussion and most helpful comments on an earlier draft. I am grateful too for the feedback provided by the audience at UNAM in Mexico in August 2016, especially from Imer Flores (the chair on that occasion), where I presented version of this paper.

\section{References}

\section{Cases}

DeShaney v Winnebago County Department of Social Services, 489 US 189 (1989)

\section{Articles / books}

ANDERSON, R. L. (1998) 'Truth and Objectivity in Perspectivism', Synthese 115: 1-32.

BALCERAK, M. (2016) 'On the Epistemic Value of Imagining, Supposing and Conceiving', in A. Kind and P. Kung (eds.), Knowledge Through Imagination. Oxford: Oxford University Press, 41-60.

COPLAN, A. (2011) 'Will the Real Empathy Please Stand Up? A Case for a Narrow Conceptualisation', The Southern Journal of Philosophy 49(s1): 40-65.

CORSO, L. (2014) 'Should Empathy Play Any Role in the Interpretation of Constitutional Rights?', Ratio Juris 27(1): 94-115. 
HARTNER, M. (2012) 'Multiperspectivity'. Living Handbook of Narratology. Available online: http://wikis.sub.uni-hamburg.de/Ihn/index.php/Multiperspectivity (last accessed 4 December 2016).

KIND, A. (2001) 'Putting the Image Back in Imagination', Philosophy and Phenomenological Research 62(1): 85-109.

KIND, A. (2013) 'The Heterogeneity of the Imagination', Erkenntnis 78(1): 141-59.

KIND, A. and KUNG, P. (eds.) (2016) Knowledge Through Imagination. Oxford: Oxford University Press.

LANDY, J. (2004) Philosophy as Fiction: Self, Deception and Knowledge in Proust. Oxford: Oxford University Press.

MACCORMICK, N. (2005) Rhetoric and the Rule of Law. Oxford: Oxford University Press.

MORAN, R. (1994) 'The Expression of Feeling in Imagination', The Philosophical Review 103(1): 75-106.

MORTON, A. (2013) Emotion and Imagination. Cambridge: Polity Press.

NUSSBAUM, M. (2001) Upheavals of Thought: The Intelligence of the Emotions. Cambridge: Cambridge University Press.

SMITH, A. (2002) [1759] A Theory of Moral Sentiments. Ed. K, Haakonssen. Cambridge: Cambridge University Press.

SPAULDING, S. (2016), 'Imagination Through Knowledge', in A. Kind and P. Kung (eds.), Knowledge Through Imagination. Oxford: Oxford University Press, pp. 207-226.

STEVENSON, L. (2003) 'Twelve Conceptions of Imagination', British Journal of Aesthetics 43(3): 238-259. 
Page $\mathbf{2 8}$ of $\mathbf{2 8}$

ZIPURSKY, B. (1990) 'DeShaney and the Jurisprudence of Compassion', New York University Law Review 65: 1101-1147. 